\title{
CORRECTION
}

\section{Correction: FoxP3 and Bcl-xL cooperatively promote regulatory $T$ cell persistence and prevention of arthritis development}

\author{
Rizwanul Haque', Fengyang Lei', Xiaofang Xiong', Yuzhang Wư and Jianxun Song*1,2 \\ See related research by Haque et al., http://arthritis-research.com/content/12/2/R66
}

\section{Correction}

Following publication of our recent article [1], it was brought to our attention that there are errors in Figure 5b and Supplementary Table 2.

The corrected Figure and table are given here as Figure 1 (a corrected version of Figure $5 \mathrm{~b}$ [1]) and Table 1 (a corrected version of Supplementary Table 2 [1]).

\begin{tabular}{|c|c|c|c|}
\hline \multirow{2}{*}{$\begin{array}{l}\text { Days (post } \\
\text { immunization) }\end{array}$} & \multicolumn{3}{|c|}{ Score } \\
\hline & Mig & Mig-FoxP3 & Mig-Bcl-xL-2A-FoxP3 \\
\hline 10 & $0,0,0$ & $0,0,0$ & $0,0,0$ \\
\hline 20 & $0,0,0$ & $0,0,0$ & $0,0,0$ \\
\hline 22 & $1.00,0,0.83$ & $0,0,0$ & $0,0,0$ \\
\hline 24 & $2.00,0,1.67$ & $0,0,0$ & $0,0,0$ \\
\hline 28 & $2.67,1.67,2.67$ & $0.50,0,0.50$ & $0,0,0$ \\
\hline 30 & $3.30,2.83,3.30$ & $0.50,0,1.17$ & $0,0,0$ \\
\hline 32 & $3.67,3.00,3.50$ & $0.50,1.17,1.50$ & $0,0,0$ \\
\hline 34 & $3.83,3.00,3.67$ & $1.00,1.67,1.50$ & $0.83,0,0$ \\
\hline 38 & $3.83,3.00,3.67$ & $1.17,1.67,1.83$ & $0.83,0.50,0$ \\
\hline 40 & $3.83,3.30,3.67$ & $1.50,1.67,2.00$ & $1.00,0.50,0$ \\
\hline 42 & $3.83,3.30,3.83$ & $1.50,2.00,2.17$ & $1.17,0.50,0.50$ \\
\hline 48 & $3.83,3.50,3.83$ & $2.00,2.00,2.67$ & $1.50,0.83,0.83$ \\
\hline 50 & $3.83,3.50,3.83$ & $2.00,2.17,2.67$ & $1.67,1.00,1.00$ \\
\hline 60 & $3.83,3.50,3.83$ & $2.00,2.40,3.00$ & $1.67,1.00,1.17$ \\
\hline
\end{tabular}

\section{Author details}

'Department of Microbiology \& Immunology and Penn State Hershey Cancer Institute, The Pennsylvania State University College of Medicine, 500 University Drive, Hershey, PA 17033, USA. Institute of Immunology, The Third Military Medical University, 30 Gaotanyan Street, Chongqing 400038, PR China.

\footnotetext{
*Correspondence: jus35@psu.edu

'Department of Microbiology \& Immunology and Penn State Hershey Cancer Institute, The Pennsylvania State University College of Medicine, 500 University Drive, Hershey, PA 17033, USA

Full list of author information is available at the end of the article
}

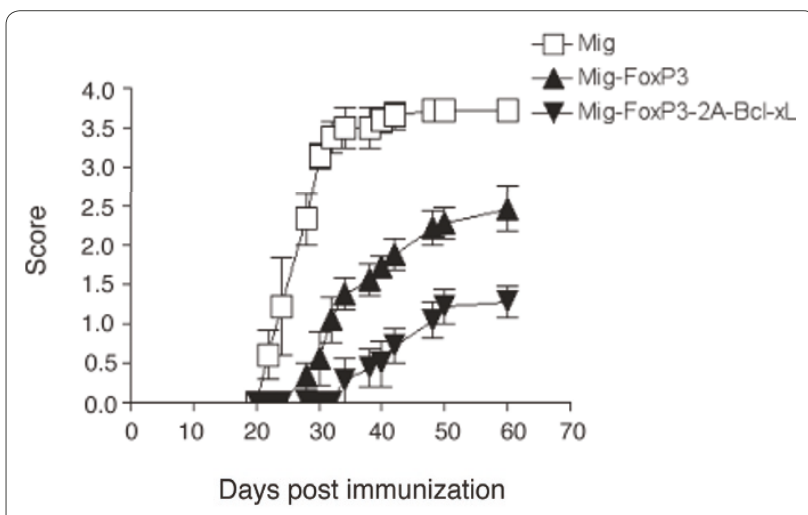

Figure 1. Adoptive cell transfer of FoxP3- and Bcl-xL-transduced regulatory $T$ cells suppresses collagen-induced arthritis (CIA).

Naive $C D 4^{+} T$ cells from DBA/1J mice were stimulated with anti-CD3 plus anti-CD28 antibodies. On days 2 and 3, the cells were transduced with retroviral constructs: vector (Mig), FoxP3 (Mig-FoxP3), or FoxP3 with BCl-XL (Mig-BCl-XL-2A-FoxP3). On day 6, green fluorescent proteinpositive $\left(\mathrm{GFP}^{+}\right) \mathrm{T}$ cells were sorted and prepared for adoptive cell transfer. CIA was induced in male DBA/1J mice ( $>4$ months old) by one (day 0) intradermal immunization in the base of the tail with $100 \mu \mathrm{g}$ of bovine type II collagen in complete Freund's adjuvant, containing $5 \mathrm{mg} / \mathrm{mL}$ killed Mycobacterium tuberculosis (H37Ra). On day 15 after the immunization, the mice received transduced GFP+ ${ }^{+}$cells $\left(2.5 \times 10^{6}\right.$ per mouse, six mice per group). In the following days, the arthritis clinical score was evaluated by examining the paws and using a 4-point scale: 0, normal paw; 1 , minimal swelling or redness; 2 , redness and swelling involving the entire forepaw; 3 , redness and swelling involving the entire limp; 4 , joint deformity or ankylosis or both. Values are the mean \pm standard error of the mean of data obtained in three experiments, and in each experiment, six mice per group were used.

Published: 10 April 2012

\section{Reference}

1. Haque R, Lei F, Xiong X, WU Y, Song J: FoxP3 and BCl-xL cooperatively promote regulatory $\mathrm{T}$ cell persistence and prevention of arthritis development. Arthritis Res Ther 2010, 12:R66.

\section{doi:10.1186/ar3790}

Cite this article as: Haque R, et al: Correction: FoxP3 and Bcl-xL cooperatively promote regulatory $T$ cell persistence and prevention of arthritis development. Arthritis Research \& Therapy 2012, 14:401. 